\title{
O processo descontínuo de recuperação paralela no Ensino Fundamental Anos Finais na aprendizagem
} em Matemática

\author{
Terezinha Marisa Ribeiro de Oliveira* ${ }^{*}$ Carmem Lúcia Costa Amaral ${ }^{\star *}$
}

\section{Resumo}

Este artigo discute a falta de continuidades das políticas públicas com relação aos projetos escolares que auxiliam os alunos com dificuldades em Matemática e apresenta o resultado da aplicação de recuperação paralela no ensino de matemática em uma escola pública do estado de São Paulo. O projeto aqui debatido e exemplificado é o Mais Educação, que era oferecido no contraturno do seu período de aula e tinha como objetivo um trabalho direcionado aos alunos que se encontravam com aprendizagem abaixo do básico. Os resultados dessa discussão e exemplificação evidenciaram que essas dificuldades, quando enfrentadas, com um professor que direcionava as atividades para essas dificuldades proporcionava uma atenção maior e elevava a autoestima do aluno, possibilitando uma melhora sensível na aprendizagem, diminuindo assim, o seu sentimento de exclusão em sala de aula.

Palavras-chaves: Ensino de Matemática. Programa Mais Educação. Recuperação Paralela.

- Doutoranda em Ensino de Ciências e Matemática pela Universidade Cruzeiro do Sul. Professora efetiva na Secretaria da Educação do Estado de São Paulo, Brasil. E-mail: terezinha.marisa@gmail.com

* Doutora em Química Orgânica pela (USP)- Universidade de São Paulo. Pesquisadora e Professora do PPG da Universidade Cruzeiro do Sul, Brasil. E-mail: carmem.amaral@cruzeirodosul.edu.br.

Recebido em: 17/08/2019 - Aceito em: 18/11/2019

https://doi.org/10.5335/rbecm.v3i2.9742

http://creativecommons.org/licenses/by-nc-nd/4.0 


\section{Introdução}

$\mathrm{O}$ ambiente escolar muitas vezes torna-se agressivo a alunos que apresentam dificuldades de aprendizagem, as quais levam a alguns problemas corriqueiros em sala de aula como a recusa em ler textos, deficiências quanto ao entendimento do que o professor está solicitando, apatia ou mesmo a indisciplina.

Nesse contexto, a Matemática torna-se um obstáculo intransponível para esses alunos, pois esta matéria já tem um histórico de exclusão, por se apresentar como difícil de aprender, e como descreve Sadovsky (2010), os professores têm a impressão que estão forçando os alunos para um universo que não os atrai.

Essa dificuldade na aprendizagem da Matemática nos remete a debater o contexto em que esta foi tratada por um longo período escolar. Costumeiramente colocada como um desafio aos alunos, apregoada como sendo para poucos, a Matemática conquistou o status como uma disciplina com alto índice de reprovação.

Os altos índices de reprovação refletem nos resultados obtidos nas avaliações externas, que por sua vez, levavam os governos federal e estadual a desenvolverem iniciativas com o intuito de minimizar esse resultado. Como professoras temos observado que algumas dessas iniciativas foram ao longo dos anos sendo colocadas em prática, mas da mesma forma que apareceram, também desapareceram de um dia para outro.

Essa descontinuidade é preocupante, pois a falta de comprometimento das políticas públicas, entre elas a recuperação paralela, proporciona um olhar diferenciado aos que por muitas vezes sentem-se excluídos ou deixados de lado em sala de aula. Muitas vezes, aquele aluno que não consegue aprender ou mesmo que tem dificuldade é rotulado por seus colegas, sofrendo bullying.

Silva (2014) e Evangelista (2016) também observaram a falta de sistematização e a fragilidade do suporte oferecido pelos órgãos responsáveis nos programas de recuperação paralela. Para esses autores, a escola deve garantir condições que garantam a sua concretização.

Neste artigo, apresentamos um exemplo de aplicação de atividades de recuperação paralela em uma escola estadual paulista e também discutimos a importância desses projetos que oferecem um auxílio aos alunos que, por algum motivo, não conseguem alcançar os objetivos propostos pela escola para desenvolver a sua 
aprendizagem em uma das mais importantes disciplinas na visão da sociedade, que é a Matemática.

\section{Alguns projetos públicos para a recuperação contínua e paralela da aprendizagem}

Com a responsabilidade de proporcionar uma aprendizagem de qualidade aos alunos, o professor deve mediar os conhecimentos e fazer com que eles aprendam e contextualizem os conteúdos com o que lhe faça sentido.

Porém, as dificuldades em conseguir fazer com que esse aprendizado se torne real exigem do professor, como enuncia Freire (2011), uma prática educativa em sua essência política. É preciso que o professor entenda que ensinar é criar possiblidades para a construção do conhecimento do seu aluno.

Para Sadovsky (2010), o conhecimento profissional acumulado permite modificar o contexto escolar, uma vez que pequenas experiências, elaboradas e executadas pelo coletivo de professores que acreditam no que foi planejado, são o caminho para quebrar a rotina insana dos problemas educacionais.

Para tanto, a autora sugere que os todos os profissionais envolvidos com a escola devem exigir melhores condições para o desenvolvimento da prática intelectual, tanto de professores como de alunos, exercendo uma pressão sobre as políticas educacionais, pois é fundamental que não se ignore o contexto social e político no qual a escola está inserida.

Para Lerner (2002, p.33), "não podemos modelar o sistema de ensino à imagem e semelhança de nossos desejos, não temos uma varinha mágica capaz de conseguir que deixe de se cumprir a função implicitamente reprodutivista da instituição escolar", e como professores não podemos renunciar a possibilidade de modificar de forma efetiva o sistema de ensino.

O sistema de ensino com políticas educacionais que são flutuantes, que a cada novo governante, novos modelos e novas fórmulas são definidas para reorganizar a instituição educacional nos parece uma tentativa de imprimir a sua marca, como um troféu ou um localizador do trabalho proposto.

Em 2008, a Secretaria de Educação do Estado de São Paulo, a partir da resolução SE 6, de 24 de janeiro de 2008, considerando os indicadores de aprendizagem dos alunos evidenciados nas avaliações externas, principalmente no Sistema de Avalia- 
ção do Rendimento Escolar do Estado de São Paulo (Saresp), dispôs sobre estudos de recuperação na rede estadual de ensino. Essas avaliações vêm demonstrando ao longo dos anos a necessidade de efetiva ação para melhoria da qualidade de ensino, e que têm como base o respeito à diversidade de características e de ritmos de aprendizagem dos alunos.

Essa Resolução definiu três tipos de recuperação: a contínua, que está inserida no trabalho pedagógico realizado no dia a dia da sala de aula; a paralela, destinada aos alunos do Ensino Fundamental e Médio com dificuldades de aprendizagem que necessitem de um trabalho direcionado e a de ciclo, quando o aluno necessita de um ano letivo de estudos para atender ciclos do Ensino Fundamental que não apresentaram condições para prosseguimento de estudos.

A recuperação paralela seria desenvolvida ao longo do ano letivo. No primeiro semestre, a partir do início de março até o final de junho, e no segundo semestre, a partir do início de agosto até o final de novembro, com os alunos com necessidades educacionais especiais incluídos em classes regulares.

As turmas eram constituídas de 15 a 20 alunos, organizadas por série, por disciplina, por área de conhecimento ou por nível de desempenho. A resolução não delimitava ou especificava a qual área deveria ser realizada a recuperação paralela, atentava para a quantidade de 3 (três) aulas semanais por turma, no mesmo turno de funcionamento da classe, após o término das aulas regulares ou fora do horário regular de aulas, inclusive aos sábados.

Essa resolução foi posteriormente revogada e foi substituída pela Resolução SE 40 de 13 maio 2008 que instituiu que por sua vez foi modificada pela Resolução SE 60 de 12 agosto de 2008 devido a dificuldade na aplicação do artigo $4^{\circ}$ da Resolução SE 40. Todas tinham como objetivo a instituição do programa de recuperação paralela como forma de sanar as dificuldades, respeitando a diversidade e os ritmos de aprendizagem para atender aos alunos do Ensino Fundamental e Médio na necessidade de superar as defasagens.

Em 2009, nova resolução entrou em vigor, a Resolução SE 18 de 4 de março de 2009, que revogou a SE 60. Essa resolução também fazia menção a uma preocupação com as avaliações externas e cita a necessidade da recuperação como uma ação para melhoria da qualidade de ensino e dispõe como princípio básico o respeito à diversidade de características e de ritmos de aprendizagem dos alunos. Essa resolução, define os períodos de recuperação paralela, o ciclo I, as atividades deveriam ser 
desenvolvidas no segundo semestre, a partir do início do mês de agosto até o final de novembro. O ciclo II e no Ensino Médio, as atividades deveriam ser desenvolvidas no primeiro semestre, a partir do mês de março até o final de julho.

De acordo com a resolução SE 18, as atividades de recuperação tinham como foco priorizar a reposição das estruturas lógico-matemáticas e linguísticas, consideradas como fundamentais para atender aos conteúdos do currículo. Novamente, esta resolução tinha como sugestão que essas atividades fossem desenvolvidas antes ou após as aulas regulares, no contraturno ou aos sábados, com 2 (duas) ou 3 (três) aulas semanais, podendo também acontecer no período de recesso do mês de julho.

Ainda em 2009, essa resolução foi revogada pela SE 92 e 93 de 08 de dezembro de 2009. A resolução SE 92, apontava sobre estudos de recuperação aos alunos do ciclo I do Ensino Fundamental das escolas da rede pública estadual, enquanto a Resolução SE 93, sobre estudos de recuperação aos alunos do ciclo II do Ensino Fundamental e do Ensino Médio das escolas da rede pública do Estado de São Paulo.

A Resolução SE 93 assegurava aos alunos de forma imediata, a recuperação contínua ou paralela, tão logo diagnosticadas as dificuldades de aprendizagem, passando assim, o professor, a contar com conjuntos indivisíveis de 10 (dez) aulas de Língua Portuguesa e de 10 (dez) aulas de Matemática destinadas ao desenvolvimento das atividades de recuperação que se fizerem necessárias ao longo do ano letivo.

Entretanto, apresentava regras conforme o número de classes: escolas com até 15 (quinze) classes, 1 (um) conjunto de cada disciplina; escolas com 16 (dezesseis) a 29 (vinte e nove) classes, 2 (dois) conjuntos de cada disciplina; e escolas com 30 (trinta) ou mais classes, 3 (três) conjuntos de cada disciplina.

Coube ao Diretor de Escola, ao Professor Coordenador, juntamente com o professor responsável pela recuperação paralela, os critérios de agrupamento dos alunos ou de formação dos grupos, o local, período e horário de realização, além de informar aos pais ou responsáveis. Deste tipo de planejamento não faziam parte os professores responsáveis pelas salas.

A proposta durou pouco tempo, pois o então Governador José Serra deixou o governo em 2010, para concorrer à Presidência da República, assumindo o vice Alberto Goldman. Apesar de serem da mesma sigla partidária, o sucessor de Alberto Goldman, no ano de 2011, foi Geraldo Alckmin, que propôs um novo modelo descrito na Resolução SE 2, de 12 de janeiro de 2012. Isso mostra o caráter de uma política 
sem um critério, com modelos pouco sedimentados em um estudo a longo prazo, mostrando uma lógica imediatista e com um viés político eleitoreiro.

Assim em 2012, o então governador do Estado de São Paulo Geraldo Alckmin lançou o programa PA (professor auxiliar), que implantou novos modelos de recuperação por meio da Resolução SE 2, de 12 janeiro de 2012.

A resolução levou em consideração a apropriação do currículo escolar de forma contínua nos Ensinos Fundamental e Médio, considerando os diferentes ritmos de aprendizagem e a necessidade de atendimento à diversidade apontadas nos diferentes diagnósticos escolares. Assim, adotou alternativas para promover aprendizagens contínuas e exitosas, conferindo mecanismos de apoio ao trabalho do professor (SÃO PAULO, 2012).

As metodologias e os momentos em que foram oferecidas as recuperações foram o diferencial, caracterizando-se por serem Contínuas e Intensivas, contando com um Professor Auxiliar (PA) nas classes regular do Ensino Fundamental e Médio; o PA tinha como função essencial à de apoiar o professor responsável pela classe ou disciplina no desenvolvimento, com vistas à superação de dificuldades e necessidades identificadas em seu percurso escolar. Assim, a atuação do PA foi desenvolvida no horário regular de aula com atendimento individualizado ou em grupo (SÃO PAULO, 2012).

O PA teria sua designação caso as classes do Ensino Fundamental ultrapassassem, respectivamente, 25 (vinte e cinco) alunos nos anos iniciais, 30 (trinta) nos anos finais e 40 (quarenta) no Ensino Médio. As classes dos anos finais do Ensino Fundamental e do Ensino Médio poderiam contar com até 3 (três) PA, respeitada a natureza da disciplina e a área de formação acadêmica dos professores, que no decorrer do ano letivo, apoiavam o docente responsável pela disciplina. Esta resolução revogou as Resoluções as Resoluções SE 92 e 93 (SÃO PAULO, 2012).

Este projeto também não vingou. É preciso grifar que estes projetos sem uma continuidade não ajudam a sanar as dificuldades dos alunos que continuam com baixo rendimento nas avaliações, principalmente na disciplina de Matemática.

O Governo Federal também imprimiu a sua marca, demarcando território no processo de recuperação paralela, por meio do Programa Mais Educação e, posteriormente, o Novo Mais Educação. O primeiro, instituído pela Portaria Interministerial 17/2007 e pelo Decreto Presidencial 7083/2010, teve como objetivo de desenvolver ações que visam integrar o Plano de Desenvolvimento da Educação - PDE. Este 
programa foi utilizado pelo Governo Federal, com o objetivo de ampliar o tempo de permanência no âmbito escolar na perspectiva da Educação Integral.

O programa Mais Educação apostava em um modelo de ação intersetorial entre as políticas públicas educacionais e sociais, com o objetivo de contribuir para a diminuição das desigualdades educacionais e a valorização da cultura brasileira, com a participação de vários Ministérios, como o da Educação, da Cultura e do Esporte, do Meio Ambiente, do Desenvolvimento Social e Combate à Fome, da Ciência e da Tecnologia e também da Secretaria Nacional de Juventude, passando a contar em 2010, com o apoio do Ministério da Defesa (BRASIL, 2011).

O projeto Mais Educação transitava pelos macrocampos, com caráter optativo pelos estudantes e compreendia: acompanhamento pedagógico; educação ambiental; esporte e lazer; direitos humanos em educação; cultura e artes; cultura digital; promoção da saúde; comunicação e uso de mídias; investigação no campo das ciências da natureza e educação econômica.

O macrocampo que não era optativo e que nos interessa é o do acompanhamento pedagógico, com as áreas de Ciências, Filosofia e Sociologia, História e Geografia, Letramento, Línguas Estrangeiras, Matemática, Tecnologias de Apoio a Alfabetização. Esse espaço foi utilizado pelas escolas para diminuir a evasão e a repetência, funcionando no contraturno das aulas. O Programa inicialmente atendeu às escolas que apresentavam baixo Índice de Desenvolvimento da Educação Básica (IDEB), situadas em capitais e regiões metropolitanas.

O Programa Mais Educação foi substituído pelo Novo Mais Educação, que foi criado pela Portaria MEC no 1.144/2016 e regido pela Resolução FNDE no 17/2017; funcionou como uma recuperação paralela, sendo criado pelo Ministério da Educação com o objetivo de melhorar a aprendizagem em Língua Portuguesa e Matemática no Ensino Fundamental, ampliando a jornada escolar.

O Programa funcionou durante todo o ano letivo de 2017, com aulas no turno e contraturno. A proposta foi de ampliação e melhoria da Língua Portuguesa e Matemática, com claros objetivos de reduzir o abandono e a reprovação, buscando melhoria nos resultados da aprendizagem do Ensino Fundamental, nos Anos Iniciais e Finais.

As propostas de recuperação paralela, que em sua grande maioria vêm com um programa enumerando as várias atividades a serem desenvolvidas na escola, com um atrelamento ao acompanhamento pedagógico não era opcional e sim obrigatório. 
As atividades desenvolvidas no contraturno contavam com a alimentação para os alunos que frequentavam o programa, avaliação diagnóstica para analisar as dificuldades que apresentavam e uma interação com os professores das classes regulares para a continuidade do trabalho.

Esse programa propunha uma continuidade em 2018, com o acompanhamento pedagógico em Língua Portuguesa e Matemática e o desenvolvimento de atividades nos campos de artes, cultura, esporte e lazer, com o aumento da carga horária em cinco ou quinze horas semanais, mas teve folego apenas para os primeiros meses do ano e como tantos outros, teve o seu encerramento.

Existem muitas críticas a esses tipos de programa, que são descontínuos e apenas aparecem quando se quer mídia, para Schermack e Sant'Ana (2018) no Estado de São Paulo tais prática são adotadas frequentemente com programas de recuperação com formatos variados que iniciam e desaparecem de maneira rápida e inesperada.

\section{Matemática: ensino ou exclusão}

Com as exigências de uma sociedade globalizada a escola pública procura com suas deficiências, uma fórmula mágica que dê conta do aprendizado dos alunos. Entretanto, nessas escolas a aprendizagem é apenas um dos contextos implícitos, outros são as desgastantes jornadas dos professores, o pouco tempo para planejamento com seus pares, os baixos salários e a formação inicial e continuada desses profissionais, que carecem de mais investimentos, o que para Borba (2006) e Oliveira (2016) apontam para uma precarização da escola básica.

Se para a escola básica, a Matemática é um problema, para os alunos que estão em uma situação abaixo do básico em sua aprendizagem, a dificuldade em sua aprendizagem é um problema ainda maior, pois leva-os a perderem a autoestima, a apatia e ao desinteresse por não conseguirem desenvolver suas potencialidades. Schermack e Sant'Ana (2018), argumentam que não se deve procurar culpados, para se ter justificativas da não aprendizagem dos alunos.

Com tantas dificuldades, a Matemática, no contexto escolar, passa a ser uma forma de exclusão, pois, muitos alunos sentem-se diminuídos, quando em sala de aula não conseguem realizar as atividades propostas pelo professor. Isso só fortalece a ideia de que a Matemática é para poucos. 
Nesse sentido, Nóvoa (2007, p. 6) indica que "é preciso insistir na ideia de centrar o foco na aprendizagem e que essa aprendizagem implica em alunos e conhecimentos", isso reforça a importância das aulas de recuperação paralela, para que a escola não se torne mais uma porta de exclusão e sim de inclusão.

Assim, para Belther (2007, p.147), "as aulas de recuperação paralela devem constituir instrumentos de discriminação positiva, pois garantem um processo pedagógico diferenciado, reduzem as diferenças decorrentes das desigualdades sociais”.

A importância da recuperação paralela está no contexto em poder ajudar a aumentar a autoestima e melhorar a aprendizagem do aluno em Matemática, incluindo este na aprendizagem juntamente com seus colegas e diminuindo as defasagens.

Para Lopes e Tremmell (2009), a recuperação paralela é um direito do aluno, que deve ser rigorosamente planejada e avaliada conforme as dificuldades de aprendizagem de cada um, respeitando as características individuais.

Nesse aspecto, a Lei de Diretrizes e Bases da Educação no ${ }^{-9.394}$, de 20 de dezembro de 1996, em seu art. 24.. , descreve: "a obrigatoriedade de estudos de recuperação, de preferência paralelos ao período letivo, para os casos de baixo rendimento escolar, a serem disciplinados pelas instituições de ensino em seus regimentos" (BRASIL,1996).

Mesmo sendo de caráter obrigatório, tais propostas não ocorrem regulamente no Ensino Fundamental e Médio, dificultando a melhoria da aprendizagem dos alunos em Matemática, pois os professores das aulas regulares não conseguem dar conta desse processo de recuperação das defasagens dos alunos. Evangelista (2016), argumenta que a recuperação paralela ajuda a construir saberes e aprender, para que assim possam seguir os estudos no ano seguinte, destacando o ambiente favorável com a colaboração e participação de todos os envolvidos nesse processo.

Silva (2014) em sua pesquisa argumenta que é preciso que a gestão escolar promova ações para aperfeiçoar a recuperação paralela, com o objetivo de melhorar a aprendizagem dos alunos

Para Schermack e Sant'Ana (2018, p.16) "se faz necessário oferecer um suporte educacional aos alunos, tão logo sejam evidenciadas dificuldades de aprendizagem no processo educativo e não quando as dificuldades já estejam se consolidando".

A seguir apresentamos um exemplo de atividade de recuperação paralela desenvolvida em uma escola de rede estadual paulista com o objetivo de evidenciar a importância dessa recuperação na defasagem em Matemática. 


\section{Exemplo de atividade de recuperação paralela}

Participaram dessa atividade de recuperação paralela no programa Novo Mais Educação, 25 alunos das quatro turmas do $9^{\circ}$ ano do Ensino Fundamental Anos Finais. Os alunos foram organizados em grupos, conforme as defasagens que apresentavam, de acordo com a avaliação diagnóstica que os professores realizaram e as análises realizadas pelos acompanhamentos desses alunos em trajetória da sua aprendizagem na escola. Essa experiência em sala de aula ocorreu em 3 etapas (Quadro 1) que foram desenvolvidas durante o ano letivo de 2017.

Quadro 1 - Descrição e objetivos das etapas.

\begin{tabular}{|c|l|l|}
\hline Etapas & \multicolumn{1}{|c|}{ Descrição } & \multicolumn{1}{|c|}{ Objetivo } \\
\hline 1 & $\begin{array}{l}\text { Reunião com os professores e } \\
\text { coordenação das salas dos 9. } \\
\text { anos. }\end{array}$ & $\begin{array}{l}\text { Identificar os alunos com difi- } \\
\text { culdades em Matemática no } \\
\text { abaixo do básico. }\end{array}$ \\
\hline 2 & Roda de conversa. & $\begin{array}{l}\text { Buscar entender as dificulda- } \\
\text { des dos alunos, seus anseios. }\end{array}$ \\
\hline 3 & $\begin{array}{l}\text { Atividades em grupos com di- } \\
\text { versos materiais, livro didático, } \\
\text { simulada prova Brasil e Saresp. } \\
\text { Jogos dominó de tabuada e ati- } \\
\text { vidades na sala de informática, } \\
\text { exercícios da AAP (Avaliação } \\
\text { de Aprendizagem em Proces- } \\
\text { so) e materiais de avaliação do } \\
\text { Novo Mais Educação. }\end{array}$ & $\begin{array}{l}\text { Auxiliar nas atividades com os } \\
\text { gruposidualmente. }\end{array}$ \\
\hline
\end{tabular}

Fonte: Autoras

\section{Resultados da atividade de recuperação paralela}

A etapa 1 contou com a formação das turmas, com vistas nos acompanhamentos realizados na escola por parte da equipe escolar. Esse processo é discutido em grande escala nos ATPCs (Atividade de Trabalho Pedagógico Coletivo).

É comum serem usadas referências do Saresp como indicativos do aproveitamento dos estudos e a classificação quanto ao aproveitamento. O quadro 2 apresenta a classificação quanto ao nível de proficiência utilizadas pela Saresp. 
Quadro 2 - Classificação e descrição dos níveis de proficiência utilizadas no Saresp.

CLASSIFICAÇÃO E DESCRIÇÃO DOS NÍVEIS DE PROFICIÊNCIA

\begin{tabular}{|c|c|c|}
\hline CLASSIFICACCĀO & NIVEL & DESCRICĀO \\
\hline Insuficiente & Abaixo do Básico & $\begin{array}{l}\text { Os alunos, neste nivel, demonstram domínio insuficiente dos conteúdos, das competências } \\
\text { e das habilidades desejáveis para o ano/série escolar em que se encontram. }\end{array}$ \\
\hline \multirow[t]{2}{*}{ Suficiente } & Básico & $\begin{array}{l}\text { Os alunos, neste nivel, demonstram dominio mínimo dos conteúdos, das competências } \\
\text { e das habilidades, mas possuem as estruturas necessárias para interagir com a proposta } \\
\text { curricular no ano/série subsequente. }\end{array}$ \\
\hline & Adequado & $\begin{array}{l}\text { Os alunos, neste nivel, demonstram dominio pleno dos conteúdos, das competências e } \\
\text { das habilidades desejáveis para o ano/série escolar em que se encontram. }\end{array}$ \\
\hline Avançado & Avançado & $\begin{array}{l}\text { Os alunos, neste nivel, demonstram conhecimentos e dominio dos conteúdos, das } \\
\text { competências e das habilidades acima do requerido para o ano/série escolar em que se } \\
\text { encontram. }\end{array}$ \\
\hline
\end{tabular}

Fonte: http://saresp.fde.sp.gov.br

O Novo Mais Educação possibilitou no ano de 2017 que todos os alunos das turmas do 9. do Ensino Fundamental Anos Finais pudessem participar da recuperação paralela no contraturno escolar, garantidos a alimentação e um atendimento personalizado às suas dúvidas. Esse processo é reforçado por Lopes e Tremmell (2009), que descrevem que a recuperação paralela deve ser rigorosamente planejada e avaliada conforme as dificuldades de aprendizagem de cada um, respeitando as características individuais.

Definidas as turmas, iniciou-se a 2. ${ }^{\text {a }}$ etapa, que foi uma roda de conversa com os alunos sobre o que cada um pensava sobre seu desempenho e se estariam dispostos a melhorar na disciplina de Matemática. Alguns alunos que não conseguissem se expressar por meio da fala, poderiam fazê-lo por escrito. Todos os alunos ponderaram o desejo de melhorar seu aproveitamento, mas a vontade de fato era a de aprender a Matemática como seus colegas de classe.

Um dos relatos que chamou a atenção foi de um aluno do 90 ano D (Figura 1). 
Figura 1 - Depoimento de um aluno sobre seu desempenho em Matemática.

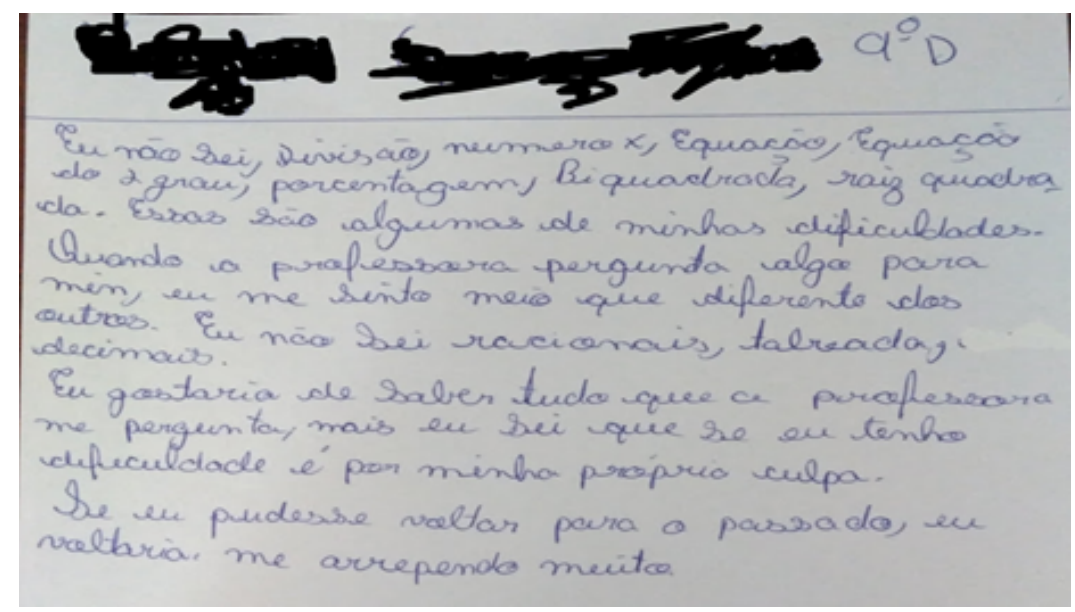

Fonte: Arquivo das autoras

Como podemos observar nesse relato do aluno, por ele não ter o domínio da Matemática, sente-se excluído, não consegue participar das aulas devido às suas dificuldades na aprendizagem e culpa a si mesmo por todo esse contexto, claramente encontra-se em uma situação fragilizada e com baixa autoestima. Assume a culpa e, apesar da pouca idade, acha que não conseguiria recuperar as suas capacidades cognitivas para melhorar a sua aprendizagem.

Esse depoimento evidencia que a Matemática se tornou um problema não somente para a escola básica como cita Borba (2006), mas também para o aluno que sofre com sua exclusão nas conversas da sala, e ao mesmo tempo reafirma seu compromisso de querer aprender, que isso faz parte do seu contexto de aprendizagem.

Para tanto, Lopes e Tremmell (2009), afirmam que na recuperação paralela devem-se respeitar as dificuldades e as características individuais de cada um. Alves (2013, p.3), acrescenta que a recuperação paralela corrobora "ao pleno desenvolvimento dos estudantes tidos como, temporalmente, de baixo rendimento"

A etapa 3 contou com diversas atividades, partindo de problemas mais simples de interpretação na resolução de problemas, pois o trabalho foi desenvolvido durante todo o ano letivo, com exceção das férias escolares de julho.

Um contexto importante foi a união da aprendizagem em sala de aula com a recuperação, o que foi também observado por Schermack e Sant'Ana (2018), que argumentam sobre a importância de se oferecer um suporte educacional logo quando 
se perceba uma dificuldade, pois só assim o professor terá possibilidade de minimizar o descompasso entre esses momentos escolares.

Nessa etapa foram desenvolvidas atividades em grupos com a utilização de diversos materiais como: o livro didático, simulado prova Brasil e Saresp, jogos de dominó sobre tabuada e atividades na sala de informática, exercícios da AAP (Avaliação de aprendizagem em processo) e materiais de avaliação do Novo Mais Educação. A Figura 2, mostra o caderno de teste que foi enviado pelo Novo Mais Educação para os alunos.

Figura 2 - Caderno de questões do Novo Mais Educação

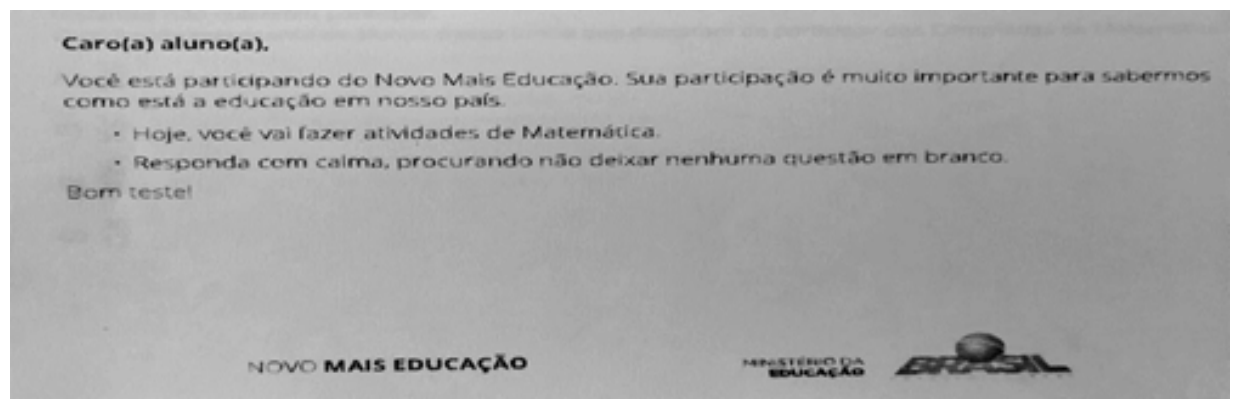

Fonte: MEC. Novo Mais Educação

Todo o trabalho foi direcionado para as defasagens apresentadas pelos alunos que se encontravam abaixo do básico nas avaliações aferidas pelos professores da sala de cada aluno participante da recuperação paralela.

O quadro 3 mostra os resultados do Saresp em Matemática para o período de 2015 a 2018 da Escola Estadual Prof. Wilson P. Miramontes da cidade de Votorantim no interior de SP.

Quadro 3 - Resultados do Saresp de Matemática na escola de 2015 a 2018.

\begin{tabular}{|l|l|l|l|l|}
\hline Níveis & \multicolumn{1}{|c|}{ Ano 2015 } & \multicolumn{1}{c|}{ Ano 2016 } & \multicolumn{1}{c|}{ Ano 2017 } & \multicolumn{1}{c|}{ Ano 2018 } \\
\hline Abaixo do Básico & 25,4 & 23,1 & 7,9 & 14,7 \\
\hline Básico & 61,0 & 59,0 & 63,2 & 62,5 \\
\hline Adequado & 12,7 & 16,2 & 26,3 & 18,4 \\
\hline Avançado & 0,8 & 1,7 & 2,6 & 4,4 \\
\hline
\end{tabular}

Fonte: http://saresp.fde.sp.gov.br

Ao analisarmos esse resultado do Saresp podemos observar que o ano de 2017 foi extremante alentador, pelo índice alcançado pela escola ao baixar de 23,1 em 
2016 para 7,9 em 2017. Esse resultado mostra que o diferencial foi a recuperação paralela intensificada ao longo do ano letivo de 2017, com alunos que apresentavam dificuldades na aprendizagem. Esse resultado resgatou a alta estima dos alunos em relação às provas que teriam que realizar.

Porém, no ano de 2018, esperávamos contar com o Novo Mais Educação e, assim, continuarmos avançando na aprendizagem dos alunos. O programa iniciou em março e só foi até a metade do ano e a escola acabou perdendo um importante aliado contra a exclusão dos alunos na disciplina de Matemática.

Esse resultado mostra a importância da recuperação paralela na aprendizagem dos alunos. Os índices também foram animadores na Prova Brasil (2017), o que mostra que um trabalho estruturado com apoio e com profissionais comprometidos é capaz de rever o movimento de exclusão do aluno.

A figura 3 mostra os resultados obtidos pela escola em 2015 no Ideb, a meta desejada pela projeção seria de 5, 2 e a escola conseguiu exatamente o 5,2 no Ideb de 2017 a meta era 5,4 e a escola alcançou 5,9 o que corresponde a meta a ser alcançada em 2021.

Figura 3 - Mostra o índice do Ideb no ano de $20178 .^{a}$ série/ $9 .^{\circ}$ ano.

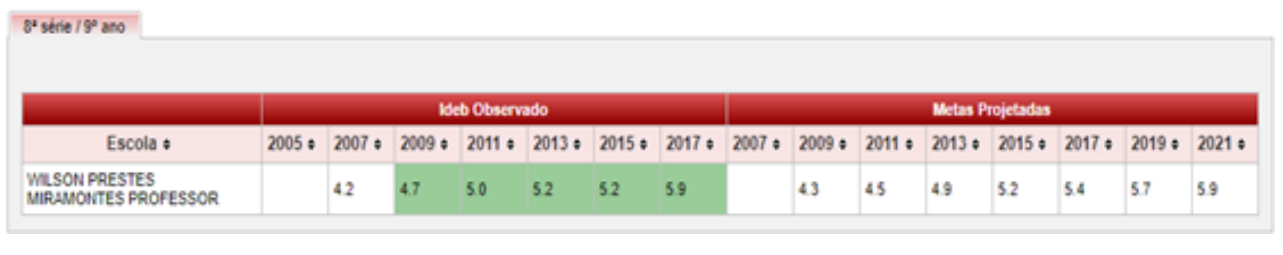

Fonte: http://ideb.inep.gov.br/resultado/

\section{Considerações finais}

A educação deve estar à frente de qualquer política governamental. Para diminuir as diferenças sociais na educação é preciso investir em aulas de recuperação intensiva ou paralela, pois só assim poderemos transformar o nosso sistema educacional, respeitando as diferenças e melhorando o convívio escolar.

Entretanto, somente com um planejamento, apoio governamental e o engajamento dos profissionais da escola será possível avançar na aprendizagem em Matemática, modificando seu status de matéria difícil de aprender, sendo para poucos iluminados. 
A escola deve estar aberta para o diálogo e não cabe nos dias de hoje dizer que o aluno não quer aprender, como professores não podemos fugir às nossas responsabilidades de auxiliar o discente a superar suas dificuldades e não o culpar pelo fracasso. Assim precisamos de uma escola que aceite suas limitações e busque alternativas para alcançar seus objetivos, que é proporcionar a conquista da cidadania aos seus alunos.

\section{The discontinuous process of parallel recovery in elementary education in the final years of Mathematics learning}

\section{Abstract}

This article discusses the lack of continuity of Public Policies related to school projects that help students with math difficulties and presents the result of application of parallel recovery in math teaching in a public school in the state of São Paulo. The projects discussed here is More Education, which had as its objective a work directed to students who, due to their difficulties, were below basic, which made it difficult for them to learn at the same pace as other students. The results of this discussion and exemplification showed that these difficulties when confronted with a teacher who directed the activities, providing a greater attention and raising the student's self-esteem, allowed a sensible improvement in the learning, reducing exclusion of the student in the classroom.

Keywords: Mathematics Teaching. More Education Program. Parallel Recovery.

\section{Referências}

ALVES, L. R. Estudos de recuperação. 2013. Disponível em: http://portal.mec.gov.br/index. php?option=com_docman\&view=download\&alias=14144-nota-sobre-estudos-recuperacao-cne-pdf\&Itemid=30192. Acesso em: 28 set. 2019.

BELTHER, J.M. Os programas de recuperação paralela e a qualidade do ensino paulista. 2007. 158 f. Tese (Doutorado em Política e Gestão Educacional). Universidade Estadual Paulista, Faculdade de Ciências e Letras de Araraquara, 2007. Disponível em: http://hdl.handle. net/11449/104783. Acesso em: 21 abr. 2019.

BORBA, M.C. Tendências internacionais em formação de professores de matemática. Belo Horizonte: Autêntica, 2006.

BRASIL. Lei de Diretrizes e Bases da Educação Nacional. Lei número 9394, 20 de dezembro de 1996. Disponível em: https://www2.senado.leg.br/bdsf/bitstream/handle/id/529732/lei_de_diretrizes_e_bases_1ed.pdf. Acesso em: 21 abr.2019.

. Ministério da Educação. Programa Mais Educação passo a passo. SEB/MEC, 2011. Disponível em: 
http://portal.mec.gov.br/component/content/article?id=16689:saiba-mais-programa-mais-educacao. Acesso em: 19 abr. 2019.

EVANGELISTA, S. O. A recuperação paralela no processo de ensino e aprendizagem: desafios da coordenadoria adjunta pedagógica da coordenadoria distrital de educação 3/SEDUC-AM. 2016, 173f. Dissertação (Mestrado em Gestão e Avaliação da Educação Pública). Universidade Federal de Juiz de Fora, Faculdade de Educação, 2016.

FREIRE, P. Pedagogia da Autonomia: Saberes necessários à prática educativa. Rio de Janeiro: Paz e Terra, $43^{\mathrm{a}}$ ed. 2011.

LERNER, D. Ler e escrever na escola: o real, o possível e o necessário. Porto Alegre: Artmed, 2002.

LOPES, R. S. P. TREMMELL, M. M. C. Recuperação Paralela: do lampião à luz solar. IX Congresso Nacional de Educação - EDUCARE - III Encontro Sul Brasileiro de Psicopedagogia. 3, 2009, Paraná (PR). Anais........Paraná, 2009. Disponível em: <http://www.pucpr.br/eventos/educere/ educere2009/anais/pdf/2271_1354.pdf>. Acesso em: 21 abr. 2019.

NÓVOA, A. Desafios do trabalho do professor no mundo contemporâneo, 2007. Disponível em: http://www.sinprosp.org.br/arquivos/novoa/livreto_novoa.pdf. Acesso em 21 abr. 2019.

OLIVEIRA, M.E. “Professor, você trabalha ou só dá aula? ": o fazer-se docente entre história, trabalho e precarização na SEE-SP. 2016, 266f.mTese (Doutorado em História) Universidade Federal da Grande Dourados. Dourados, MS: UFGD, 2016.

SADOVSKY, P. O ensino de matemática hoje: Enfoques, sentidos e desafios. 1. ed. São Paulo: Ática, 2010.

SÃO PAULO. Resolução SE no 02, de 12-1-2012. Dispõe sobre mecanismos de apoio escolar aos alunos do ensino fundamental e médio da rede pública estadual. Disponível em: http://siau. edunet.sp.gov.br/ItemLise/arquivos/02_12.HTM?. Acesso em: 21 abr. 2019.

SILVA, L.T.L. A implementação do programa de recuperação paralela e seus efeitos sobre o desempenho dos alunos no contexto da EMEIEF Rural Flor do Campo. 2014, 214f. Dissertação (Mestrado em Gestão e Avaliação da Educação Pública profissional). Universidade Federal de Juiz de Fora, Faculdade de Educação/CAEd. 2014.

SCHERMACK, L. V.; SANT'ANA, I. M. A recuperação intensiva no Estado de São Paulo: uma experiência com professoras de uma escola pública. Educ. Pesqui., São Paulo, v. 44, p.1-19, ago. 2018. 